\title{
Colonization of citrus leaves and secondary conidiation response to citrus flower extracts by non-postbloom fruit drop strains of Colletotrichum acutatum
}

\author{
Steven J. MacKenzie ${ }^{1}$, Natalia A. Peres ${ }^{1}$ \& Lavern W. Timmer \\ ${ }^{1}$ Department of Plant Pathology, Gulf Coast Research and Education Center, University of Florida, Wimauma, FL 33598, \\ USA; ${ }^{2}$ Department of Plant Pathology, Citrus Research and Education Center, University of Florida, Lake Alfred, FL 33850, \\ USA
}

Author for correspondence: Natalia A. Peres, e-mail: nperes@ufl.edu

\begin{abstract}
Postbloom fruit drop (PFD) is caused by a unique strain of Colletotrichum acutatum that infects citrus flowers, producing necrotic lesions on petals and the abscission of fruitlets. This strain survives on vegetative tissues during non-flowering periods, and conidial production on colonized tissue is stimulated by flower extracts. Genetically distinct strains from other hosts can cause PFD symptoms, but their survival on vegetative tissues and ability to sporulate in response to flower extracts is unknown. Isolates from anthracnose-affected blueberry, leatherleaf fern, strawberry, Key lime and PFD-affected sweet orange were evaluated for their ability to survive on leaves after inoculation and to produce conidia in response to flower extracts. Viable propagules were recovered from leaves inoculated with all nonPFD isolates and recovery of some was equal to or greater than that of the PFD isolate. The number of propagules recovered increased for all isolates after treatment with flower extracts and was comparable across isolates. Application of sucrose to leaves inoculated with the PFD isolate increased the number of propagules recovered from leaves, suggesting that the response to flower extracts was nutritional. Non-PFD isolates of $C$. acutatum can colonize and reproduce on leaves, and their inability to cause epidemics is probably due to their reduced pathogenicity to flowers.
\end{abstract}

Key words: etiology, anthracnose, blueberry, leatherleaf fern, strawberry.

\section{RESUMO}

Colonização de folhas de citros e formação de conídios secundários por isolados de Colletotrichum acutatum não causadores de podridão floral dos citros

A podridão floral dos citros (PFC), causada por Colletotrichum acutatum, infecta flores e produz lesões necróticas nas pétalas que induzem a abscisão de frutos jovens. O fungo sobrevive em tecidos vegetativos nos períodos entre floradas e a produção de conídios em tecidos colonizados é estimulada pela aplicação de extrato de flores. Isolados de C. acutatum de outros hospedeiros são geneticamente distintos e também podem causar sintomas de podridão floral, porém sua sobrevivência em tecidos vegetativos e sua habilidade de esporulação em resposta à aplicação de extrato de flores é desconhecida. Nesse trabalho, isolados de C. acutatum causadores de antracnose em mirtilo, samambaia-preta, morango e limão galego foram avaliados quanto à sua habilidade de sobrevivência e produção de conídios em resposta a aplicação de extrato de flores. Propágulos viáveis foram obtidos de folhas de citros inoculadas com isolados de todos os hospedeiros e a recuperação de alguns isolados foi igual ou maior do que a de isolados de PFC. O número de propágulos obtidos aumentou significativamente para todos os isolados após o tratamento com extrato de flores. A aplicação de sucrose em folhas inoculadas com um isolado de PFC também aumentou o número de propágulos obtidos, indicando que a resposta ao extrato de flores deve ser devido a nutrientes. Os resultados deste estudo indicam que isolados de C. acutatum de outros hospedeiros podem colonizar e se reproduzir em folhas de citros e sua inabilidade para causar epidemias pode ser atribuída a menor patogenicidade a flores de citros.

Palavras-chave: etiologia, antracnose, mirtilo, samambaia-preta, morango.

\section{INTRODUCTION}

Colletotrichum acutatum J.H. Simmonds is a globally distributed pathogen with a broad host range that includes dicotyledonous plants, pine, and leatherleaf fern (Peres et al., 2005). The species was first described in Australia where it was isolated from fruit of papaya, avocado, strawberry, and solanaceous crops (Simmonds, 1965). Symptoms caused by C. acutatum are often referred to as anthracnose and they include fruit rot, flower blight, foliar blight, stem necrosis, abnormal growth, premature abscission of fruit and root rot (Peres et al., 2005; Sreenivasaprasad \& Talhinhas, 2005). Although $C$. acutatum is generally viewed as a broad host range pathogen, there is considerable strain variation within $C$. acutatum, and one or a few strains are generally responsible for disease on each susceptible host (Guerber et al., 2003; MacKenzie et al., 2009; Sreenivasaprasad \& Talhinhas, 2005). Therefore, strains within C. acutatum 
have a much more limited host range than would be suggested by the wide range of hosts infected by C. acutatum as a whole. Thus, groups have been established within C. acutatum (Guerber et al., 2003; MacKenzie et al., 2009; Sreenivasaprasad \& Talhinhas, 2005; Whitelaw-Weckert et al, 2007), and some of those have now been described as the new species C. fioriniae and C. simmondisi (Shivas \& Tan, 2009).

A unique strain of $C$. acutatum is responsible for epidemics of postbloom fruit drop (PFD) of citrus throughout the Americas (Peres et al., 2008). This strain was described originally as a slow-growing orange (SGO) strain of Colletotrichum gloeosporioides (Fagan, 1979) until it was reclassified as C. acutatum (Brown et al., 1996). The PFD strain produces necrotic lesions on petals, and the lesions are sites of abundant conidium production (Timmer et al., 1994). Fruitlets from infected flowers prematurely abscise, leaving calyces that persist between flowering intervals (Timmer et al., 1994). The fungus survives as an epiphyte or biotroph during nonflowering periods on leaves, twigs, or the persistent calyces (Agostini \& Timmer, 1994). On these vegetative tissues, conidia germinate and form appressoria, but no visible symptoms are evident and infections do not appear to progress beyond the formation of an infection peg (Agostini et al., 1992; Zulfiqar et al., 1996). In response to flower extracts, both hyphae and secondary conidia are produced from colonized vegetative tissues, and it is hypothesized that this response may be used to time sporulation to flowering periods (Agostini \& Timmer, 1994; Zulfiqar et al., 1996). Similarly, secondary conidiation by $C$. acutatum on strawberry leaves is stimulated by strawberry flower extracts (Leandro et al. 2003). Secondary conidiation on strawberry during flowering is also a potential mechanism by which the fungus can time sporulation from vegetative tissues to fruit production periods.

MacKenzie et al. (2009) examined the genetic variation of isolates that cause anthracnose on blueberry, strawberry, leatherleaf fern, and Key lime and those that cause PFD on citrus flowers in Florida. They found isolates from the same host were identical to one another genetically, with the exception of isolates from leatherleaf fern, where three unique strains were present. None of the strains were found on more than one host, indicating that the strains are host specific or have a limited host range. In pathogenicity assays, isolates caused disease primarily on the host from which they were acquired. However, with the exception of leatherleaf fern isolates, all of the isolates produced necrotic lesions on tangelo flowers and a high percentage of infected flowers formed persistent calyces. The symptoms were quantitatively less than observed with PFD isolates, but were sufficient to suggest that the isolates from these other hosts could contribute to a disease epidemic. Agostini et al. (1994) also noted that Key lime anthracnose (KLA) isolates produced significant PFD symptoms on sweet orange flowers.

Given that non-PFD strains can produce PFD symptoms on citrus (MacKenzie et al., 2009), their virtual absence in groves where PFD is present suggests that nonPFD strains may lack the ability to persist on vegetative tissue between blooms or fail to time spore production from vegetative tissues to correspond to flowering periods (Zulfiqar et al. 1996). The objective of the present study was to determine if $C$. acutatum strains, other than those responsible for PFD, have the ability to germinate on citrus leaves and survive and whether conidiation is stimulated by citrus petal extracts, as occurs with the PFD strain of C. acutatum (Agostini,et al. 1992; Zulfiqar et al. 1996).

\section{MATERIALS AND METHODS}

\section{Isolates}

Five isolates were selected from the study by MacKenzie et al. (2009) in which the genetic relationship and host ranges of $C$. acutatum isolates from Florida were characterized. The isolates were: OCO-ARC-4 (group J), from PFD-affected sweet orange (Citrus sinensis Osbeck) flowers; Hm-1 (group J), from Key lime [C. aurantiifolia (Christm.) Swingle] foliage; 02-163 (group D) from strawberry (Fragaria $\times$ ananassa) fruit; 05-88 (group C) from blueberry (Vaccinium corymbosum) fruit; and 05-161 (group J) from leatherleaf fern (Rumohra adiantiformis) leaves using the groups described by Guerber et al. (2003) and MacKenzie et al. (2009). Suspensions of conidia used for inoculations were prepared from 5- to 7-day-old cultures grown on potato dextrose agar (PDA) at $23^{\circ} \mathrm{C}$ under constant light. Conidia were washed from culture plates with sterile water, filtered through four layers of cheesecloth, and diluted to $2.5 \times 10^{6}$ conidia $/ \mathrm{mL}$ unless otherwise specified.

\section{Microscopy}

To view conidia from the surface of leaves, a solution of clear nail polish (Sally Hansen Advanced Hard as Nails; Coty US LLC, Morris Plains, NJ) was applied over the inoculated area and allowed to dry at room temperature. After drying, the nail polish was stripped off the leaf with forceps and stained with lactophenol blue solution (50 mg methyl blue, $25 \mathrm{~g}$ phenol, $25 \mathrm{~g} \mathrm{~L}(+)$-lactic acid, $50 \mathrm{ml}$ glycerol in $100 \mathrm{ml}$ aqueous solution; Fluka Analytical, Buchs, Switzerland). Digital images at $\times 400$ and $\times 1000$ magnification were made using an Olympus BX41 microscope and the Olympus Q-Color5 imaging system (Olympus Corporation, Tokyo) after inoculated sites were incubated $48 \mathrm{~h}$ under high humidity and following treatments with sterile water, flower extract, or $2.5 \%$ sucrose solution.

\section{Germination and survival on leaves}

C. acutatum conidia are able to germinate on plastic and other hard surfaces (Leandro et al. 2003; Parbery \& Blakeman, 1978), indicating that well-defined topographical cues do not regulate germination in this species. However, 
substances associated with the leaf surface may affect appressorium formation (Parbery \& Blakeman, 1978). In this study, citrus leaves were considered to be colonized by $C$. acutatum if the fungus could be recovered from surface disinfested leaves after inoculation. Although surface disinfestation has been used previously to quantify asymptomatic endophytic colonization of plant tissues by $C$. acutatum (Freeman et al., 2001), preliminary experiments were conducted to determine the conidial concentration for inoculations, spore germination and survival and appressorium formation.

\section{Conidial concentration for inoculations}

An ideal concentration of conidia would produce a viable colony on fewer than $100 \%$ of sites inoculated with citrus isolate OCO-ARC-4, while still producing a sufficient number of colonized sites to easily discriminate between the colonization efficiency of this isolate and isolates that colonize less effectively. The conidial concentration to be used for inoculations was determined by inoculating greenhouse-produced leaves with $0,500,1,000,10,000$, 25,000 , and 50,000 conidia of isolate OCO-ARC-4 in $10 \mu \mathrm{L}$ of water and counting the number of colonies that formed on the CIM selective medium (12 $\mathrm{g}$ of potato dextrose broth, $17 \mathrm{~g}$ of agar, $100 \mathrm{mg}$ of streptomycin, $250 \mathrm{mg}$ ampicillin, $0.02 \%$ tergitol and $4 \mathrm{mg}$ a.i. iprodione (Rovral 50WP, Bayer Crop Science LP, Research Triangle Park, NC) per liter) from leaves surface-disinfested with $0.53 \%$ sodium hypochlorite and inoculated with the different densities of spores at 9 days post inoculation. Once the mean number of colonies/conidium was determined, the proportion of inoculated sites expected to produce at least one viable colony at a range of inoculum levels was calculated using the Poisson distribution (Ott \& Longnecker, 2001). The proportion of inoculated sites expected to produce at least one viable colony was equal to $1-\lambda^{k} e^{-\lambda} / k$ !, where $k=0$ and $\lambda=$ the number of conidia applied to a site multiplied by the mean number of colonies/conidium.

\section{Spore germination and survival}

An experiment was conducted to determine whether spore germination was required to obtain colonies from surface-disinfested leaves. For this, leaves were inoculated with $10 \mu \mathrm{L}$ of a suspension of $2.5 \times 10^{6}$ conidia $/ \mathrm{ml}$ of isolate OCO-ARC-4 at 40 marked sites. Twenty of these sites were sprayed with sterile water and leaves bagged for $48 \mathrm{~h}$ and 20 were left dry. At $72 \mathrm{~h}$ after inoculation, leaves were surfacedisinfested with $0.53 \%$ sodium hypochlorite and placed on CIM. Also, conidia stripped from leaves using the nail polish technique described under microscopy above were examined to determine the effect of treatments on germination.

\section{Germination and appressorial formation}

An experiment was conducted to determine the percent of spores for each isolate that germinated and formed appressoria on tangelo leaves and to evaluate whether the formation of infection structures was consistent across isolates. For this experiment, three suspensions of each isolate containing $1 \times 10^{5}$ conidia $/ \mathrm{mL}$ were prepared from separate plates. Ten $\mu \mathrm{L}$ of each suspension were placed at marked sites on leaves and the suspension was allowed to dry. Subsequently, the leaves were sprayed with sterile distilled water and bagged for $48 \mathrm{~h}$. The conidia were removed from leaves using the nail polish technique described above, and the percentage of conidia with appressoria in each isolateinoculum preparation combination was determined for at least 25 conidia. Differences between isolate means were compared using a one-way analysis of variance.

\section{Survival after disinfestation}

In the primary experiment, the quantitative measure used to determine the ability of isolates to colonize leaves was the percent of inoculated leaf sites that produced a colony on growth media after sites were surface disinfested. We assumed that if all fungal structures on the surface of leaves were killed by disinfestation, then colonies formed from leaves when plated on media would be derived from subcuticular fungal structures or resistant structures on the leaf surface. Five- to 10-year-old, potted Orlando tangelo (C. reticulata Blanco $\times$ C. paradisi Macfad.) trees were used for all inoculations. Ten- $\mu \mathrm{L}$ drops of a $2.5 \times 10^{6}$ conidia $/ \mathrm{mL}$ suspension or sterile water (negative control) were placed on 2-week-old shoots containing three to six leaves at four to six marked sites per leaf. Leaves were allowed to dry and then shoots were sprayed with deionized water, covered with plastic bags, and the trees were placed outside in a protected, shaded area for $48 \mathrm{~h}$. After $48 \mathrm{~h}$, bags were removed from the shoots and the trees were moved to a greenhouse. Inoculations were done on four dates (23 May, 6 June, 9 July, 15 August 2007), and isolates from each host were used to inoculate two shoots on at least 18 sites per shoot (36 total inoculation sites) on each date. For each isolate, 12 leaf pieces containing a separate inoculation site were cut from leaves and placed in $0.53 \%$ sodium hypochlorite at 9,18 , and 27 days after inoculation. Following $30 \mathrm{sec}$ of surface disinfestation, as in previous studies (Agostini et al. 1994; Zulfiqar,et al., 1996), pieces were rinsed twice in sterile water and then placed on CIM. Six days after placement on CIM, leaf pieces were scored for the presence or absence of $C$. acutatum colonies. Where the scoring of leaf pieces for the presence of $C$. acutatum colonies was ambiguous due to contaminating fungi, colonies were placed on PDA supplemented with benomyl to distinguish it from $C$. gloeosporioides (Peres et al., 2004). On each of the three dates after inoculation, the percent of leaf pieces colonized by $C$. acutatum (number colonized/12 $\times 100 \%$ ) isolates from each host was recorded.

\section{Propagule production on inoculated leaves in response to flower extracts}

Petal extracts were made by grinding petals with 3 parts (wt:vol) sterile water using a mortar and pestle as in previous studies to induce PFD isolates to sporulate 
on citrus leaves (Agostini \& Timmer, 1994). Petals were collected from sweet orange trees in 2007 and 2008 during the spring bloom and were stored at $-80^{\circ} \mathrm{C}$. The extract was filtered once through four layers of cheesecloth, centrifuged for $5 \mathrm{~min}$ at 3,000 $\times \mathrm{g}$ and filtered through Whatman No. 5 filter paper (Whatman International, Maidstone, England). The soluble solids content of a petal extract as measured by refractometry was $2.5 \%$ brix.

Two or four 2-week-old Orlando tangelo shoots per isolate were inoculated on eight dates (two shoots per isolate inoculated 30 May and 17 Sep 2007; four shoots per isolate inoculated 14 and $26 \mathrm{Mar}, 7$ and $14 \mathrm{Apr}$, and 20 and 27 Aug 2008). On three leaves of each shoot, three areas were marked. Each marked area was inoculated with $10 \mu \mathrm{l}$ of a suspension of $2.5 \times 10^{6}$ conidia $/ \mathrm{mL}$ or water (negative control) and incubated in a plastic bag for 48 $\mathrm{h}$ as described above. At 4 weeks post inoculation, one (2007) or two (2008) shoots per isolate were sprayed with water and an equal number of shoots sprayed with flower extract. Shoots were covered with a plastic bag and trees were placed outside in a shaded area for $48 \mathrm{~h}$. After the $48 \mathrm{~h}$ exposure to flower extract or water, three inoculated leaf pieces were removed from each shoot and placed in $7.5 \mathrm{~mL}$ of sterile water. After vortexing twice for $20 \mathrm{sec}$, $100 \mu \mathrm{L}$ of the water was spread onto a $10-\mathrm{cm}$ diameter plate containing CIM. CIM plates were incubated at $25^{\circ} \mathrm{C}$ under continuous light and C. acutatum colonies counted after 3 or 4 days incubation.

\section{Effect of sucrose}

A $2.5 \%$ sucrose solution $(2.5 \mathrm{~g}$ sucrose per $100 \mathrm{~mL})$ was tested on three additional dates using the PFD isolate to assess the effect of a sugar on stimulation of propagule production. The experiment was conducted in the same manner as the experiment using flower extract except that there were 2 rather than 4 weeks between inoculation and application of flower extracts, each treatment was replicated five to six times on each date, and $200 \mu \mathrm{L}$ rather than $100 \mu \mathrm{L}$ of suspended propagules washed from leaves was used to seed plates. For water-, flower extract-, and sucrose-treated leaves, propagules washed from inoculation sites were all recorded as the number of colonies per inoculation site.

\section{Viability of propagules}

An experiment was conducted to determine the number of propagules on the surface of the leaf that were viable after inoculations and to determine if only $C$. acutatum that successfully colonized tissue was stimulated by flower extracts or if viable fungal structures on the surface of the plant could also respond to extracts. The frequency with which inoculated sites responded to extracts indicated that fungus at the plant surface was stimulated to grow and produce conidia in response to extracts. To quantify the total number of propagules that remained viable after inoculation, suspensions containing 10, 100, 1000, or 10,000 conidia of isolate OCO-ARC-4 in $1 \mu \mathrm{L}$ sterile distilled water were inoculated on marked sites on leaves after the leaves had been wiped with ethanol to reduce contamination. For each suspension, seven to ten marked sites on three attached leaves were inoculated. After the inoculated surfaces had dried, the leaves were sprayed with sterile water, covered with a plastic bag, and incubated for $48 \mathrm{~h}$. The marked sites were placed on CIM without surface disinfestation 5 days after the incubation and scored for the presence or absence of a $C$. acutatum colony 3 days later. Attempts to examine viability at times later than five days post inoculation failed due to contamination of leaf surfaces. Furthermore, suspensions of 50, 500, or 5000 conidia in 2.5 $\mu \mathrm{L}$ of sterile distilled water were placed on 9 to 16 sterile coverslips in 10-cm diameter petri dishes at $95 \%$ humidity for $48 \mathrm{~h}$. After $48 \mathrm{~h}$, the coverslips were inverted onto CIM and coverslips were scored for the presence or absence of $C$. acutatum colonies after 3 days. The incidences of inoculated leaf sites and conidium-treated coverslips that failed to produce a C. acutatum colony after application of 1000 or 500 conidia, respectively, were used to estimate the proportion of conidia applied that remained viable on each substrate. When 1000 conidia were applied to leaves or 500 conidia applied to coverslips, the percentage of leaves or coverslips that produced a colony on CIM was between 0 and 100. At these incidences, the percent of conidia remaining viable could be estimated by substituting the proportion sites without a colony and the number of conidia initially applied into the equation for the Poisson distribution with $k$, the number of occurrences, equal to 0 (Ott \& Longnecker, 2001). Thus, the $\%$ viable conidia $=-\ln$ (proportion sites without a colony $) \times 100 /$ number of conidia applied.

\section{Statistical analysis}

Factors affecting the percentage of inoculated sites producing colonies after surface disinfestation were assessed using a generalized mixed model logistic analysis. The PROC MIXED and the \% GLIMMIX macros were used for this analysis (SAS Institute, Cary, NC). In the model, proportions transformed using the logit link function were described by the fixed effects "isolate", "days after inoculation" and "isolate $\times$ days after inoculation" and the random effects "inoculation date" and "inoculation date $\times$ isolate". The effect "inoculation date" accounts for variation in temperature or leaf phenology at the time of inoculation and the effect "inoculation date $\times$ isolate" accounts for variation in the calculated concentration of conidia for individual isolates on each inoculation date. Variability in colonization incidence was assumed to follow a binomial distribution. Differences between isolate means were evaluated using the LSMEANS statement and PDIFF option. Overall fixed treatment effects were evaluated with $F$ statistics.

Log-transformed values for colonies per inoculation site were analyzed using a generalized mixed model with PROC MIXED (SAS Institute, Cary, NC). The equation for the transformation was log (colonies per inoculation 
site +1$)$. This transformation was used to equalize variance across treatments and inoculation dates and eliminate treatment $\times$ isolate effects that would arise if the extract treatment had a multiplicative effect on propagule production. For the experiment examining the effect of flower extracts on propagule production across multiple isolates, fixed effects were "isolate", "extract" (water vs. extract) and "isolate $\times$ extract". Random effects were "inoculation date" and "inoculation date $\times$ isolate". Again, these random effects were included in the model to account for variation in temperature or leaf phenology at the time of inoculation and the calculated concentration of conidia for individual isolates on each inoculation date. Differences between "isolate $\times$ treatment" means were evaluated using the LSMEANS statement and PDIFF option. The effect of sucrose on propagule production from leaves was examined using a model that included "sucrose" (water vs. sucrose) as the only fixed effect and "inoculation date" as the only random effect. For both generalized mixed models, overall fixed treatment effects were evaluated with $F$ statistics.

\section{RESULTS}

\section{Germination and survival on leaves}

Conidial concentration for inoculations. The mean number of colonies obtained per conidium applied was 0.000045 . Based on this result, $10 \mu \mathrm{L}$ of a suspension of 2.5 $\times 10^{6}$ conidia/mL $(25,000$ conidia $)$ was expected to produce quiescent infections on $68 \%$ of the leaves after 9 days.

Spore germination and survival. Conidia germinated on leaves that had been wetted and covered with a bag, but not dry leaves. Eleven of the 20 inoculated sites with germinated conidia produced colonies after surface disinfestation, whereas none was observed from leaves on which conidia failed to germinate.

Germination and appressorial formation. The percentage of conidia that germinated and formed appressoria ranged from $39 \%$ to $66 \%$ for isolates from each of the five hosts. The mean percentages were not significantly different among isolates from the different hosts $(P=0.42)$. Variation in the percent germination of conidia between leaves was high and contributed to the inability to discriminate between isolates. Conidia from each host produced a short germination tube and a single melanized appressorium (Figure 1). An internal light spot was evident within the appressoria, indicating that infection pegs had formed (Diéguez-Uribeondo et al., 2003).

\section{Survival after disinfestation}

Isolates varied in their ability to withstand surface disinfestation (Figure 2, $F_{4,12}=9.8, P<0.001$ ), indicating that isolates differed in their ability to successfully colonize citrus. The ability to withstand surface disinfestation was stable over time for each isolate, because the proportion of

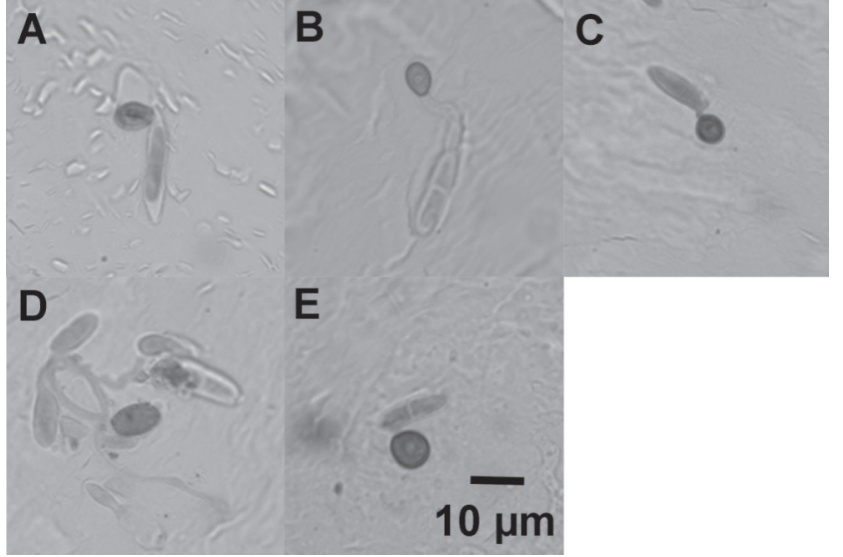

FIGURE 1 - Germinated conidia of Colletotrichum acutatum isolates on tangelo leaves $48 \mathrm{~h}$ after inoculation: A. OCO-ARC-4 (postbloom fruit drop - sweet orange), B. Hm-1 (Key lime), C. 02163 (strawberry), D. 05-88 (blueberry), and E. 05-161 (leatherleaf fern). The original host for or disease caused by each isolate is shown in parentheses.

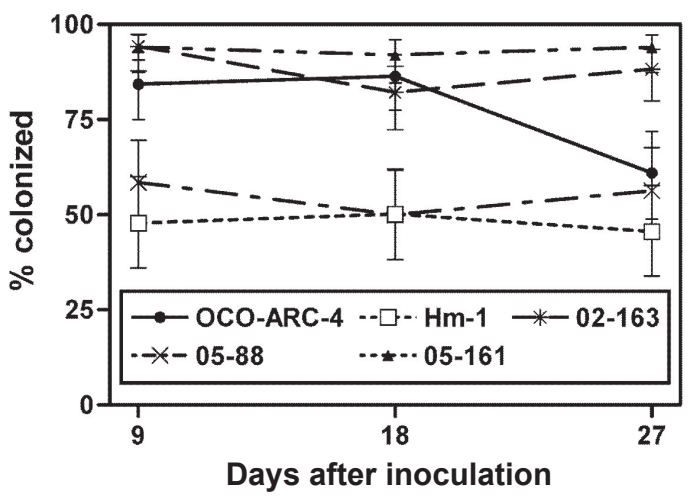

FIGURE 2 - Percent colonization of tangelo leaves by Colletotrichum acutatum isolates at 9, 18 and 27 days after inoculation. Isolates with their disease or host of origin in parentheses are: OCO-ARC-4 (postbloom fruit drop - sweet orange), Hm-1 (Key lime), 02-163 (strawberry), 05-88 (blueberry), and 05-161 (leatherleaf fern). Error bars represent the standard errors of the mean.

leaf pieces producing colonies averaged over all isolates did not differ between 9,18 , and 27 days after inoculation $\left(F_{2,30}\right.$ $=0.86 ; P=0.43$ ) and the interaction effect, "isolate $\times$ days after inoculation" was not significant $\left(F_{8,30}=0.90 ; P=0.53\right)$. The percent recovery of $C$. acutatum from sites inoculated with the fern isolate (05-161) and strawberry isolate (02163) was as high as or higher than that for the PFD isolate (OCO-ARC-4) (Table 1). The percent recovery from sites inoculated with the blueberry (05-88) and KLA (Hm-1) isolates was lower than recovery from sites inoculated with the PFD isolate. C. acutatum was not recovered from noninoculated leaves (data not shown). 


\section{S.J. MacKenzie et al.}

\section{Propagule production on inoculated leaves in response to flower extracts}

There was a significant effect of isolate $\left(F_{4,28}=5.16\right.$, $P<0.003)$ and flower extract $\left(F_{1,95}=58.13, P<0.001\right)$ on the number of colonies that grew from leaf washes of inoculation sites. There was no evidence for an "isolate $\times$ extract" effect $\left(F_{4,95}=1.52, P=0.204\right)$. Analysis of $\log$ transformed and backtransformed means indicated that flower extracts had a primarily multiplicative effect on colony counts across isolates as opposed to an additive effect (Table 2). The $P$-value for $t$-tests comparing water- to flower extract-treated leaves was less than 0.01 for all isolates except the strawberry isolate (02-163), which had a $P$-value of 0.06 (Table 2 ). The ratio of backtransformed colonies from flower extract- to water-treated leaves ranged from 3.63 for the strawberry isolate (02-163) to 41.6 for the leatherleaf fern isolate (05-161). Ratios were sensitive to colony counts from water-treated leaves and the leatherleaf fern isolate produced few colonies in the absence of extract (Table 2). Without this isolate, ratios ranged from 3.63 to 11.89. For sites treated with water or flower extract, there were fewer colonies washed from sites inoculated with PFD isolate OCO-ARC-4 than from Key lime isolate Hm-1 (Table 2). Colony count means for sites inoculated with blueberry, strawberry, and leatherleaf fern isolates were not statistically different $(P>0.05)$ from the mean for sites inoculated with OCO-ARC-4 (Table 2). Microscopic evaluations of isolates on leaves after treatment with water or flower extract 28 days post inoculation confirmed that the increase in the number of colonies obtained from leaf washes in response to flower extract application was due to increased growth of and production of conidia from isolates on leaves (Figure 3 ). The citrus isolates (Hm-1 and OCO-ARC-4) appeared to have more hyphae than other isolates and greater hyphal growth for these isolates was particularly evident after treatment with flower extract (Figures 3B and 3H).

TABLE 1 - Mean percent colonization of surface-disinfested tangelo leaves with Colletotrichum acutatum isolates from five hosts over three times after inoculation

\begin{tabular}{lcl}
\hline \hline Isolate code (host) & ${ }^{2}$ & Percent colonization (logit [percent colonization]) $^{\mathbf{3}}$ \\
\hline 05-161 (leatherleaf fern) & $93.3(2.640)$ & $\mathrm{a}$ \\
02-163 (strawberry) & $89.2(2.108)$ & $\mathrm{ab}$ \\
OCO-ARC-4 (sweet orange) & $79.0(1.323)$ & $\mathrm{b}$ \\
05-88 (blueberry) & $54.9(0.198)$ & $\mathrm{c}$ \\
Hm-1 (Key lime) & $47.8(-0.087)$ & $\mathrm{c}$ \\
\hline
\end{tabular}

Percent colonization is the backtransformed value of the mean logit value for four inoculations at 9, 18 and 27 days after inoculation with specified isolate. The mean logit is reported in parentheses.

${ }^{2}$ Anthracnose-affected species are identified by the common name of the host. The sweet orange isolate is from flowers affected by postbloom fruit drop.

${ }^{3}$ Means followed by the same letter were not significantly different $(\mathrm{P}=0.05)$ according to least square means $\mathrm{t}$ tests of the logit transformed means. The critical difference between logit means required to separate them varied with the isolates being compared, but ranged from 0.925 to 1.344 .

TABLE 2 - Mean number of colonies washed from sites of tangelo leaves inoculated with Colletotrichum acutatum isolates from five hosts after treatment with sterile water or flower extract 4 weeks after inoculation ${ }^{1}$

\begin{tabular}{|c|c|c|}
\hline \multirow[b]{2}{*}{ Isolate code (host) ${ }^{2}$} & \multicolumn{2}{|c|}{$\begin{array}{c}\text { Colonies/inoculation site } \\
(\log [\text { colonies/inoculation site }-1])\end{array}$} \\
\hline & Water $^{3}$ & Flower extract ${ }^{3,4}$ \\
\hline Hm-1 (Key lime) & $217(2.338) \mathrm{a}$ & $2581(3.412)^{* * *} \mathrm{a}$ \\
\hline 05-88 (blueberry) & $156(2.195) \mathrm{ab}$ & $1270(3.104)^{* *} \mathrm{ab}$ \\
\hline 02-163 (strawberry) & $96(1.990) \mathrm{ab}$ & $349(2.544)^{*}$ \\
\hline OCO-ARC-4 (sweet orange) & $34(1.548) \mathrm{bc}$ & $294(2.469) * *$ \\
\hline 05-161 (leatherleaf fern) & $7(0.913) \mathrm{c}$ & $291(2.465) * * * \quad b$ \\
\hline
\end{tabular}

${ }^{1}$ Mean number of colonies are the backtransformed values of the mean for transformed values reported in parentheses.

${ }^{2}$ Anthracnose-affected species are identified by the common name of the host. The sweet orange isolate is from flowers affected by postbloom fruit drop.

${ }^{3}$ Means followed by the same letter within columns were not significantly different $(P>0.05)$ according to least square means $t$ tests of the transformed means. The critical difference required to separate means was 0.722 .

${ }^{4}$ Asterisks indicate the level of significance for least square means $t$ tests evaluating the effect of flower extracts on colonies recovered for individual isolates. $* P<0.1, * * P<0.01$, and $* * * P<0.001$. A difference between treatments of 0.585 or greater was required to observe a $P$-value of $\leq 0.05$. 

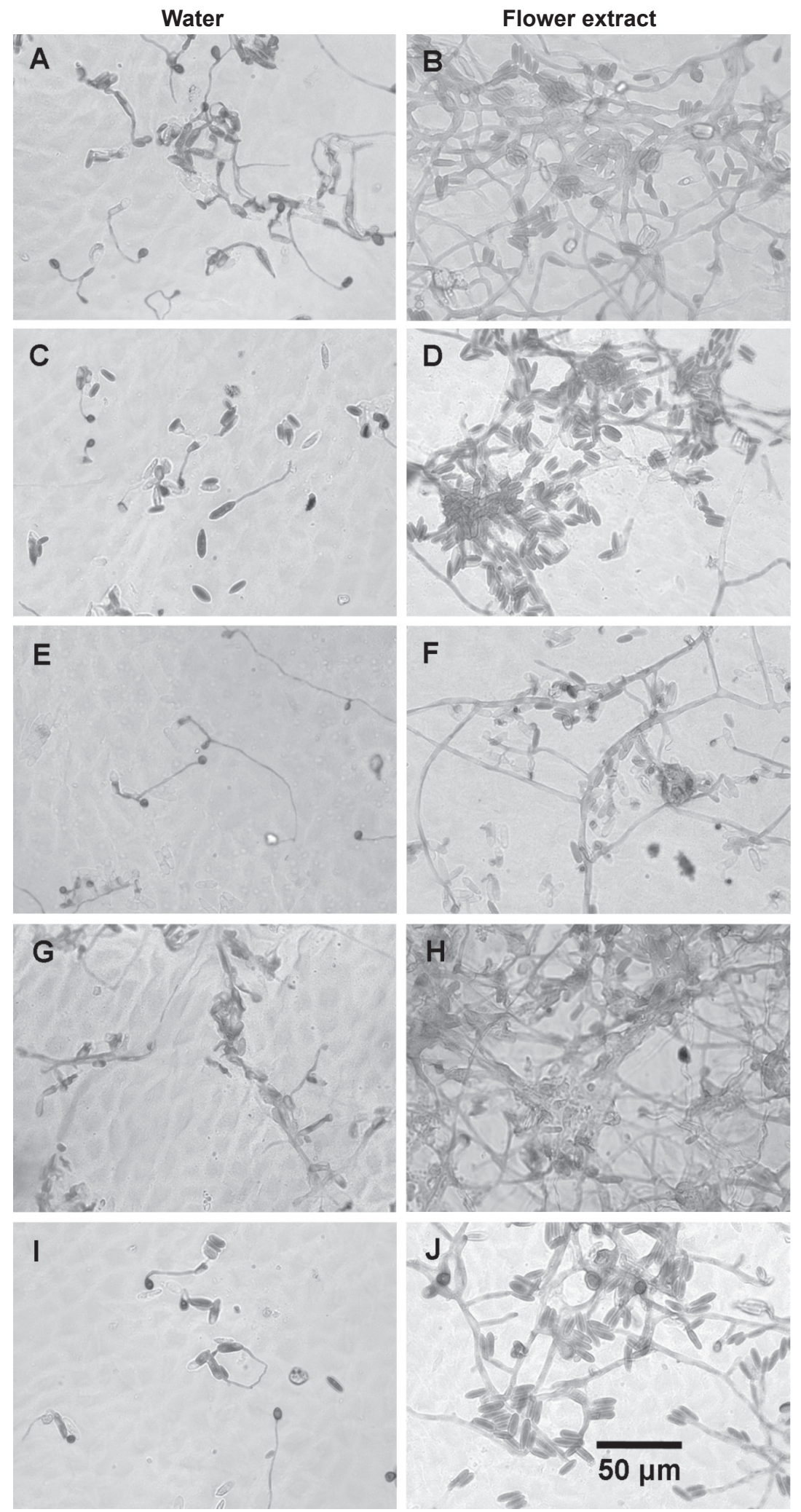

FIGURE 3 - Conidia, hyphae, germination tubes, and appressoria stripped from tangelo leaves inoculated with Colletotrichum acutatum isolates: $\mathbf{A}$ and $\mathbf{B}, \mathrm{Hm}-1$ (Key lime), $\mathbf{C}$ and D, 05-88 (blueberry), E and F, 02-163 (strawberry), G and $\mathbf{H}$, OCO-ARC-4 (postbloom fruit drop - sweet orange), and I and J, 05-161 (leatherleaf fern). Strips A, C, E, G, and I were from leaves treated with water for $48 \mathrm{~h}$, and strips $\mathbf{B}, \mathbf{D}, \mathbf{F}, \mathbf{H}$, and $\mathbf{J}$ were from leaves treated with citrus flower extract for $48 \mathrm{~h}$. 


\section{S.J. MacKenzie et al.}

\section{Effect of sucrose}

A treatment with $2.5 \%$ sucrose increased the number of colonies recovered from sites inoculated with PFD isolate OCO-ARC-4 from 47.1 to $280.8\left(F_{1,28}=9.99, P=0.004\right)$. Similar to the response to flower extract, both conidium production and hyphal growth appeared to be stimulated by $2.5 \%$ sucrose (Figure 4 ).

\section{Viability of propagules}

The number of leaf sites inoculated with OCOARC-4 that produced a C. acutatum colony on CIM was 0 of 7 for sites inoculated with 10 conidia, 0 of 7 for sites with 100 conidia, 6 of 10 for sites with 1,000 conidia and 10 of 10 for sites with 10,000 conidia. For coverslips, 0 of 15 treated with 50 conidia, 5 of 16 treated with 500 conidia, and 9 of 9 treated with 5,000 conidia produced colonies on CIM. Based on data for sites inoculated with 1,000 conidia or coverslips treated with 500 conidia, the percentage of conidia that remained viable after incubation under favorable conditions for germination was $0.092 \%$ on leaves and $0.075 \%$ on coverslips.

\section{DISCUSSION}

The results of this study indicate that the C. acutatum strain responsible for most PFD symptoms throughout the Americas does not have a unique ability to form quiescent infections on vegetative tissue between flowering intervals or to time sporulation to flower production. Of the four non-PFD isolates examined, only the fern isolate did not produce PFD symptoms on flowers (MacKenzie et al., 2009). Therefore, blueberry, KLA, and strawberry strains could potentially contribute to PFD epidemics, with KLA isolates being the only ones besides PFD isolates that have been recovered from PFD-affected sweet orange flowers (Peres et al., 2008). KLA and blueberry isolates did not colonize vegetative tissue to the extent that the PFD isolate did, which may explain why these strains are not commonly isolated from PFD-affected petals. However, overall there was no clear trend that the PFD strain was more likely to colonize leaves or that it produced more propagules in response to flower extracts than other isolates.

A C. acutatum strain that causes anthracnose on strawberry was shown to colonize tomato, eggplant, and pepper (Freeman et al., 2001). Similar to our results, the strawberry strain produced no visible symptoms on the other hosts, the ability to form quiescent infections was not host specific, and recovery from asymptomatic surfacedisinfested tissue changed little for up to seven weeks in the absence of overhead irrigation. In that study, viable propagules were also recovered from leaf washes, and recovery declined by two orders of magnitude after seven weeks (Freeman et al., 2001). The authors indicated that the colonies recovered from washed leaves were nongerminated conidia that declined in viability over time. Agostini and Timmer (1994) noted a low rate of recovery of C. acutatum from surface-disinfested tissue, even when the number of colonies recovered in surface washes was high. They suggested that the incidence of quiescent infections was low, although a large proportion of conidia germinated and remained viable.

In the present study, the viability of non-germinated conidia, germinated conidia or appressoria formed from conidia was estimated to be less than 0.1 percent on leaves or on coverslips after incubation under conditions favorable to germination. However, the number of conidia that formed quiescent infections at 9 days was estimated to be about one-tenth this value. Although very low, the high number of viable spores or fungal structures on the surface of leaves relative to quiescent infections likely explains why viable spores can be obtained from tissue washes when the incidence of isolations from surface disinfested tissue is low. Results of our study differed from those of Agostini and Timmer (1994) in that the percent isolation from surface disinfested leaves did not decline after approximately 4 weeks. This might have been due to the
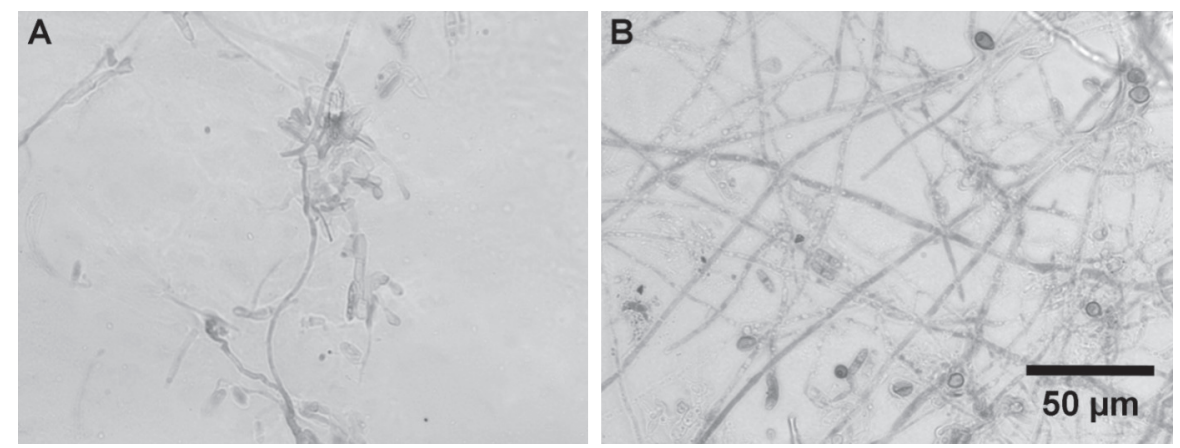

FIGURE 4 - Conidia, hyphae, germination tubes and appressoria stripped from tangelo leaves inoculated with Colletotrichum acutatum isolate OCO-ARC-4 from a postbloom fruit drop- affected flower petal: A. inoculated leaves treated with water for $48 \mathrm{~h}$ and B. inoculated leaves treated with $2.5 \%$ sucrose for $48 \mathrm{~h}$. 
different PFD isolate used in their study or the inoculation procedure. The inoculation procedures differed in that a higher concentration of inoculum was used in the present experiment, but a smaller area of leaf was used to recover isolates after surface disinfestation.

Flower extracts have been shown to stimulate secondary conidiation by $C$. acutatum strains from both strawberry and PFD-affected citrus (Agostini \& Timmer, 1994; Leandro et al., 2003). Only flower extracts from the host of origin were used to stimulate conidiation in those studies and, to our knowledge, this was the first study to determine that flower extracts from an alternative host could stimulate secondary conidiation. The lack of spore production in response to flower extracts by $C$. gloeosporioides on citrus suggested that not all strains of C. acutatum would respond to citrus extracts (Agostini \& Timmer, 1994). There was an 8.6-fold increase in the number of colonies washed from sites inoculated with the PFD strain of $C$. acutatum. This response appears to be normal for PFD isolates when colonies recovered from washed leaves are used to assess increased conidiation, because an almost identical 8.5-fold response to flower extracts was reported for a different PFD isolate (Agostini $\&$ Timmer, 1994). Sucrose produced a 6-fold increase in the number of colonies washed from inoculated sites, which was comparable to the response to flower extract. This indicates that the growth and sporulation of C. acutatum strains in response to flower extract treatment does not require any complex chemical cues that might limit the range of hosts capable of eliciting the response, and that an increase in the availability of sugar is probably the response stimulus. Other fungi that are plant pathogens also appear to produce spores in response to sugar availability. Sporulation by Colletotrichum lindemuthianum in culture was stimulated by glucose, sucrose, xylose and galactose (Mathur et al., 1950) and a mixture of simple sugars stimulated budding by Taphrina deformans (Rossi \& Languasco, 2007).

In conclusion, there was no evidence that the ability to form endophytic infections on citrus tissues resistant to disease confers a selective advantage to the PFD strain when flowers, the tissue susceptible to disease development by the PFD strain, do not occur on the host. Also, citrus flower extract failed to stimulate production of propagules in a manner that would indicate that it provides a strain-specific cue to time sporulation to flower development. Based on these results, some other factor must explain why the PFD strain is almost exclusively isolated from groves with PFD. A plausible reason for the fact that the PFD strain is almost exclusively isolated from PFD-affected groves is simply that it is more pathogenic to flowers. There was a clear trend indicating that PFD isolates were more pathogenic than the strawberry, KLA and blueberry isolates because they infected $90 \%$ to $100 \%$ of flowers, whereas isolates from these other hosts infected only $27 \%$ to $47 \%$ percent of flowers (MacKenzie et al., 2009).

\section{ACKNOWLEDGMENTS}

This project was supported by the United States Department of Agriculture Tropical Subtropical Agricultural Research program. We thank Catalina Moyer for technical assistance.

\section{REFERENCES}

Agostini JP, Timmer LW (1994) Population dynamics and survival of strains of Colletotrichum gloeosporioides on citrus in Florida. Phytopathology 84:420-425.

Agostini JP, Timmer LW, Mitchell DJ (1992) Morphological and pathological characteristics of strains of Colletotrichum gloeosporioides from citrus. Phytopathology 82:1377-1382.

Brown AE, Sreenivasaprasad S, Timmer LW (1996) Molecular characterization of slow-growing orange and Key lime anthracnose strains of Colletotrichum from citrus as C. acutatum. Phytopathology 86:523-527.

Diéguez-Uribeondo J, Förster H, Adaskaveg JE (2003) Digital image analysis of internal light spots of appressoria of Colletotrichum acutatum. Phytopathology 93:923-930.

Fagan HJ (1979) Postbloom fruit drop, a new disease of citrus associated with a form of Colletotrichum gloeosporioides. Annals of Applied Biology 91:13-20.

Freeman S, Horowitz S, Sharon A (2001) Pathogenic and nonpathogenic lifestyles in Colletotrichum acutatum from strawberry and other plants. Phytopathology 91:986-992.

Guerber JC, Liu B, Correll JC, Johnston PR (2003) Characterization of diversity in Colletotrichum acutatum sensu lato by sequence analysis of two gene introns, mtDNA and intron RFLPs, and mating compatibility. Mycologia 95:872-895.

Leandro LFS, Gleason ML, Nutter FW Jr, Wegulo SN, Dixon PM (2003) Strawberry plant extracts stimulate secondary conidiation by Colletotrichum acutatum on symptomless leaves. Phytopathology 93:1285-1291.

MacKenzie SJ, Peres NA, Barquero MP, Arauz LF, Timmer LW (2009) Host range and genetic relatedness of Colletotrichum acutatum isolates from fruit crops and leatherleaf fern in Florida. Phytopathology 99:620-631.

Mathur RS, Barnett HL, Lilly VG (1950) Sporulation of Colletotrichum lindemuthianum in culture. Phytopathology 40:104-114.

Ott RL, Longnecker MT (2001) An Introduction to Statistical Methods and Data Analysis. 5th ed. Pacific Grove CA. Duxbury Press.

Parbery DG, Blakeman JP (1978) Effect of substances associated with leaf surfaces on appressorium formation by Colletotrichum acutatum. Transactions of the British Mycological Society 70:7-20.

Peres NA, MacKenzie SJ, Peever TL, Timmer LW (2008) Postbloom fruit drop of citrus and Key lime anthracnose are caused by distinct phylogenetic lineages of Colletotrichum acutatum. Phytopathology 98:345-352.

Peres NAR, Souza NL, Peever TL, Timmer LW (2004) Benomyl sensitivity of isolates of Colletotrichum acutatum and $C$. gloeosporioides from citrus. Plant Disease 88:125-130. 
Peres NA, Timmer LW, Adaskaveg JE, Correll JC (2005) Lifestyles of Colletotrichum acutatum. Plant Disease 89:784-796.

Rossi V, Languasco L (2007) Influence of environmental conditions on spore production and budding in Taphrina deformans, the causal agent of peach leaf curl. Phytopathology 97:359-365.

Shivas RG, Tan YP (2009). A taxonomic re-assessment of Colletotrichum acutatum, introducing C. fioriniae comb. et stat. nov. and C. simmondsii sp. nov. Fungal Diversity 39:111-122.

Simmonds JH (1965) A study of the species of Colletotrichum causing fruit rots in Queensland. Queensland Journal of Agriculture and Animal Science 22:437-459.

Sreenivasaprasad S, Talhinhas P (2005) Genotypic and phenotypic diversity in Colletotrichum acutatum, a cosmopolitan pathogen causing anthracnose on a wide range of hosts. Molecular Plant Pathology 6:361-378.

Timmer LW, Agostini JP, Zitko SE, Zulfiqar M (1994) Postbloom fruit drop of citrus, an increasingly prevalent disease of citrus in the Americas. Plant Disease 78:329-334.

Whitelaw-Weckert MA, Curtin SJ, Huang R, Steel CC, Blanchard CL, Roffey PE (2007) Phylogenetic relationships and pathogenicity of Colletotrichum acutatum isolates from grape in subtropical Australia. Plant Pathology 56:448-463.

Zulfiqar M, Brlansky RH, Timmer LW (1996) Infection of flower and vegetative tissues of citrus by Colletotrichum acutatum and $C$. gloeosporioides. Mycologia 88:121-128.

TPP 92 - Received 25 March 2010 - Accepted 20 December 2010 Section Editor: Francisco F. Laranjeira 